\title{
Librarians and Teaching Faculty: Partners in Bibliographic Instruction
}

\section{David Carlson and Ruth H. Miller}

The integrated model of bibliographic instruction (BI) appears to be the preferred method of instruction despite such concerns as high cost in time and personnel. But even more crucial concerns are (1) a critical dependence on teaching faculty, (2) the difficulty of achieving a consistent, even program of instruction, and (3) the problem of transference of library knowledge from one course to another. As more emphasis is placed on research strategies than on specific tools, it becomes clear that the relationship between librarians and faculty is the major element in a successful BI program.

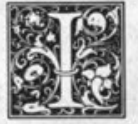

$t$ is surely a sign of maturity when bibliographic instruction (BI) can be seriously discussed as a separate discipline rather than just another subfield of librarianship. ${ }^{1}$ Within the past two decades there has been a tremendous growth in BI programs and literature. Yet, despite all this activity and interest, it is impossible to identify an approach or concept that clearly defines the movement. For some, $\mathrm{BI}$ is little more than traditional reference service with a library orientation tour for freshmen students added on. For others, it represents a pervasive approach based on "concepts, theoretical frameworks, and mental processes that guide sound library research."'2 Methods also differ widely. Workbooks, computer-assisted instruction, credit courses, non-credit courses, point-of-use instruction, integration, term paper clinics, and pathfinders are all legitimate, well-used approaches to reach the common goal of teaching students how to use the library.

One reason for this diversity of approach is the sometimes hectic growth of
BI itself. As a movement, it has roots and some history. ${ }^{3}$ The frequent exchange of ideas in the literature and activity in the classroom, however, indicate that the maturing of the discipline is a recent phenomenon. Another reason for the many approaches to BI is that each has its own unique strengths and weaknesses. ${ }^{4}$ Diversity allows the librarian to choose the most appropriate approach in view of available resources and institutional strengths. The librarian usually chooses the method that will best meet the objectives of the BI program. For example, is the program to be selective and reach only certain target groups such as freshmen or is the approach to be comprehensive without excluding any group or subject area? The librarian should assess these important factors in order to ensure that the best approach is selected.

This paper focuses on critical factors regarding the effectiveness of the courserelated or course-integrated mode of BI. Course-related or course-integrated programs share three common characteristics:

David Carlson is systems analyst at the University Library, University of Rhode Island, Kingston, Rhode Island 02881, and Ruth H. Miller is collection development librarian, University of Evansville, Evansville, Indiana 47702 . 
1. Integration with the Curriculum. Instruction is given as part of subjectspecific classes in the curriculum. Typically, the classes have an assignment such as a term paper to complete that involves use of the library.

2. Faculty Involvement. Because instruction on the use of the library is given as part of subject-specific classes, librarians must work extensively with and have the cooperation of the faculty who teach these classes.

3. Group Instruction. Lectures are given by librarians to groups of students in a class and not to individuals. This does not preclude small group instruction or individual assistance.

These basic characteristics set the integrated approach apart from other models of BI. Apart from this, however, courseintegrated programs differ widely. Often these differences relate to the extent of the interaction between librarian and faculty member. In some programs the librarian's role is quite limited, and a BI lecture is given solely to meet the requirements of the course assignment; here BI is approached strictly as the means to a specific end. In other programs, BI is an integral part of the course, almost inseparable from primary course content. In this case, the librarian and faculty member may work together as a team. Course objectives and course design are built around library assignments. ${ }^{5}$

Integration offers important advantages: flexibility, the ability of the librarian to reach a relatively large number of students at one time, and increased motivation for students to learn through the class assignment. Other important benefits are the heightened visibility of the library and the enhanced role of the librarian in the educational process.

Course-related instruction can have a large impact on the courses themselves, the students, and even the curriculum, by exposing both students and faculty to sophisticated research skills and to a wider range of library materials than they normally would have used. Courserelated instruction can be a great image builder for both the library as the center for learning and knowledge and the librarian as a serious researcher and professional interested in furthering the teaching-learning process. Librarians get to know faculty and students more intimately and can offer suggestions on teaching and researching procedures. ${ }^{6}$

The role and image of the librarian can change substantively in an integrated approach. In lecturing to classes, the librarian is seen clearly by students as an active participant in the educational process, rather like a guest speaker with specialized expertise in an area of interest to the class. Thus, integrated BI allows the librarian to move away from a role of passive guardian and caretaker of the collection to that of active participant, teacher, and information specialist. The most important benefit of integration, however, is that through the relationship developed between librarians and faculty, "the nature of the courses themselves may change, with more emphasis placed on independent library investigation as an integral part of the course. "'

Heightened visibility and increased participation of librarians in the educational process enable these educational and curricular changes to take place. These changes are especially important to academic librarians who believe they are a critical part of the educational process but often have little to show for that belief. These changes are the direct result of librarians going outside the library to work with faculty and to teach students in the classroom. By definition, this type of activity is integrated. No other approach enables the librarian to take such an active and effective part in the educational role of the institution.

In addition to these important benefits, integration receives "a good press." The program at Earlham College is one of the oldest, most effective and successful programs in the country. Evan Farber and other librarians at Earlham have been instrumental in the promotion of BI. Earlham librarians have pointed with pride to their program as an example of integrated instruction that is effective for the library and is an essential part of the educational process. Who could fault them?

Because of the unique and important advantages of integration and the success of the Earlham model, it is not surprising that many librarians view this model as 
the preferred method of instruction.

Conference presentations and informal conversations at bibliographic instruction meetings in the last few years have been filled with assertions that course-related and course-integrated instruction are the ideals to be achieved.

Or, as another author asked after reviewing the advantages offered by the integrated approach,

What prevents course-related instruction from universal acceptance as the preferred means of library instruction? ${ }^{9}$

Once the integrated model is accepted, what impact will it have on the curriculum? Will the program be as successful as the one at Earlham? What factors will both hinder and promote the achievement of BI goals? These are the questions that maturity brings. These are the questions that now face BI librarians.

\section{PROBLEMS OF THE INTEGRATED MODEL}

In reviews of the integrated approach to $\mathrm{BI}$, administrative problems are most frequently identified and discussed. Some of these are as follows:

1. Cost in Time and Personnel. In an integrated program, the librarian spends a significant amount of time preparing for lectures. This has been identified as "one of the major problems" of integration. ${ }^{10}$ One recent estimate is that the time needed to prepare a single presentation is ten to fifteen hours. ${ }^{11}$ This is clearly a significant cost, considering a librarian's other day-to-day responsibilities. Fortunately this high investment is lessened if the presentation is repeated frequently. Thus, once a presentation is fully developed and refined to the satisfaction of the librarian and the teaching faculty, only the review and update of resources are necessary before reuse. It must be noted, however, that this base of experience is built only with time and "no matter how many times a core lecture is reused, at least a half day is involved in careful reformating or modification." 12

2. Coordination and Scheduling. Because this form of instruction is so dependent on integration with the curriculum, the librarian must coordinate and respond to a flexible class schedule. Among the necessary and basic functions that must be performed for the program to function are: knowing the size and location of the class, gathering information about changes in class assignment, working with timing constraints imposed by the lecture, and contacting professors.

Other characteristics complicate the coordination of integrated programs. First, instruction is typically needed all at once toward the beginning of each term. Second, key variables change from term to term and year to year. Of course, the extent of these problems is directly related to the level of instructional activity. The coordination of five to ten lectures per term is trivial but the coordination of two or three lectures a day during the first few weeks of a term can be a formidable administrative problem. Moreover, unlike the time required for lecture preparation, the work of coordination does not substantially decrease over time.

3. Materials Development. Nearly all integrated programs use a variety of instructional materials to supplement lectures: slides, transparencies, handouts, books, or a combination of these materials. Each type of material has different requirements for handling and use. All require time to organize and maintain. Some can be costly to duplicate and need to be redesigned with each new lecture.

Two other administrative problems are the teaching skills of the librarian and the difficulty of evaluation. The problems of preparation time, coordination and scheduling, and materials development should not be minimized. However they are all administrative concerns over which the librarian has a great deal of control. Demands on time and personnel constraints can be controlled by limiting the number of lectures and the material used for teaching; difficulties of coordination can be solved through the application of efficient procedures and effective lines of responsibility.

These administrative concerns are not the primary, critical areas that ultimately will determine the effectiveness of an integrated program. Rather, they are only the problems that appear most formidable for a new program. Other problems over 
which the librarian has less control are much more troublesome and may have a greater impact on a program's ultimate success. The authors have identified three such areas. They are (1) a critical dependence on teaching faculty, (2) the difficulty of achieving a balanced program of instruction, and (3) the problems of transference of library-based knowledge from one course to another. Beyond simple identification, discussion on these areas in the literature has been limited. Effective solutions to these difficult problems will not come quickly or easily, but the first valuable step toward maturity is usually an identification and appreciation of the complexity before us.

\section{THE CRITICAL ROLE OF FACULTY}

No matter how hard librarians work, without the cooperation and support of teaching faculty, the BI program will be unsuccessful or severely limited. This happens because the attitude of the faculty is a major determinant in the response of students to the program. As Raymond McInnis notes:

More than any other factor, the value the classroom instructor attaches to library research determines the students' interest in use of library materials. Instructors give direction and motivation to students as to how library materials are to be used in meeting course requirements. Their influence is most often the difference between a perfunctory use of materials and dedicated examination of the rich store of scientific literature typically available in most college libraries. ${ }^{13}$

Most reference and BI librarians will affirm the accuracy of McInnis' observation. More than any other method of instruction, the integrated model is extremely dependent on faculty for success.

The dependence of the BI librarian on the faculty member manifests itself in several ways. The initial and most obvious manifestation, of course, is the difficulty of convincing the faculty member to allow the BI librarian to address the class at all. On every campus there are faculty with no interest in using BI in their classes. Among faculty willing to schedule presentations, there is a wide diversity of interest in and value attached to BI. For some faculty, the presentation will never be more than a filler for a session that they must miss. Others approach BI with interest but with little knowledge of its value or purpose. Once lectures are scheduled, faculty who are enthusiastic and knowledgeable about BI may work with the librarian to produce assignments encouraging students to use library resources creatively and systematically.

On the other hand, if a professor uses BI out of some vague feeling of obligation but with no definite sense of its value, students will easily perceive this attitude. Students will then have an ample excuse to view the BI session-or the assignments-as unimportant. Even when the librarian is welcomed into the class, there is seldom any chance to participate in determining the nature of the assignment itself. Preparation becomes more difficult and the librarian is denied involvement in the evaluation of the final product. The absence of involvement and authority is not lost on students.

While the librarian is not usually involved in the assignment, the faculty member often has specific ideas and suggestions about the library presentation. Faculty may insist on specific, and often inappropriate, sources being presented to the class. At best, these suggestions support a specific assignment, and the inclusion of the suggested resources, made on the basis of the faculty member's experience with the research literature, may be a valuable addition to the librarian's presentation. On the other hand, the inclusion of a source because of the professor's appreciation of it, regardless of its suitability for the students and the assignment, may complicate the presentation and confuse the students.

Occasionally a professor will devise a bibliographic treasure hunt for students, with the idea that this process will teach them a great deal about using the library. This is a list of questions for which students must find highly specific answers, frequently in obscure or unfamiliar sources or by subtle means. While this may be of value in some contexts and even enjoyable if freely chosen, such a method is likely to confuse and frustrate many students, especially those for whom libraries 
are unfamiliar or even alien places. Instead of emphasizing a research strategy or demonstrating how to proceed systematically, such exercises emphasize randomness and suggest that one may just as well ask the librarian to find things because there is no meaningful system or discoverable order. Many faculty who use BI expect their students to be told only about specific tools rather than concepts on research strategy and are satisfied, frequently even impressed, with modest nods to the theoretical. While it is important for the faculty member to be present when lectures are given and to be involved in the BI process, he or she should not be encouraged or expected to designate the specific tools to be presented.

The integrated model usually gives the librarian at least one and seldom more than four class sessions. The best use of that limited time can be made if the professor has a well chosen assignment, a supportive attitude, and awareness of the uses and purpose of the library and BI. Librarians may insist on a library assignment as a prerequisite for a classroom presentation, but they can hardly insist on a "proper" attitude and an "approved" assignment. While the "instructor provides the stimulation and motivation necessary to get most students seriously concerned about engaging in research," the librarian provides the process for doing so effectively. ${ }^{14}$ This means working with both faculty and students.

\section{CONSISTENCY OF INSTRUCTION}

One advantage of a separate course in library skills is that the student population is clearly defined and it is possible to tailor presentations precisely. The workbook approach has similar advantages. Both modes provide control over who takes the class and may even offer control over when it is taken, e.g., as a graduation requirement. With the control provided by a workbook or a separate course, the librarian works with a relatively uniform level of library skills and progresses in a logical, predetermined series of lectures and exercises to teach library skills. The greater similarity in the students' experience and the greater likelihood of correctly target- ing problem areas increases the opportunity for successful presentations.

The integrated model, however, gives the librarian very little control over who is reached or when. In making a presentation to a specific class, the librarian may have to lecture to students at several different levels of library skill and knowledge. The material in the presentation will be completely new and unfamiliar to some; for others it will be full of the same basic resources used in other lectures, explained yet again.

Student motivation is a key element in any instructional program, and one sure method to destroy it is through repetitive instruction. ${ }^{15}$ One possible response to this problem is to allow those students who feel that they do not need the instruction to leave. However, an invitation to leave for a qualified few frequently results in the unqualified departure of many. Students who know only the use of Reader's Guide and the card catalog may think there is no reason for them to remain for further instruction. They will not have been made aware of or exposed to the complexity and variety of other sources. It is unfortunate that almost all students-regardless of their actual level of bibliographic skillregard their skills as being quite good and view themselves as competent library users.

There is an even greater problem resulting from the wide diversity of library skills among students. In the attempt not to lose those for whom the lecture is the first library presentation of any sort and not to alienate those for whom it is repetitive, the elaboration of lectures that present a consistent, logical progression of skills is an elusive goal. It is extremely difficult to progress beyond fundamental library resources and research skills when the librarian cannot assume a common base of knowledge on which to build.

The lack of control over who receives instruction can also result in a very uneven program. The inclusion of a library instruction presentation is dependent on the cooperation and voluntary support of individual faculty members. As classes are taught by different professors, the degree of receptivity toward the inclusion of a library presentation will vary. Indeed, it is 
possible to have two or more sections of the same course taught during the same term by different professors with some sections receiving $\mathrm{BI}$ and others not. By graduation there can be a wide range of library skills, not just in the student body as a whole but even within disciplines.

One means of dealing with this problem is to impose a structure on the BI program. For example, the Earlham program is:

... gradated into four levels of instruction, according to students' needs. Briefly, these four levels may be identified as: pre-freshmen coming from high school with varying library knowledge, freshmen writing their first 'research' paper, juniors beginning their majors, and seniors trying to integrate their four years. $^{16}$

Another approach taken at the University of Evansville is to offer a formal program of progressively more complex library instruction to a school or department and have it approved by the teaching faculty as a group. At Evansville specific classes are selected to receive library instruction and specific educational objectives to be achieved with each level of instruction are identified. ${ }^{17}$ It can be extremely difficult, however, to get a group of faculty to agree on a proposal that, in essence, mandates the inclusion of specific subject material. Another response to the problem of consistency is to restrict instruction to those classes where a common level of library skills can be assumed. This may severely limit the number of class presentations.

\section{TRANSFERENCE OF LIBRARY KNOWLEDGE}

The third area of concern is the transferability of library knowledge from one course to another. Even for highly motivated students who are receptive to $\mathrm{BI}$ and recognize its value, it may be extremely difficult for them to transfer such knowledge to other courses or even to other assignments. It is helpful if students are guided through specific assignments, but then what? If nothing else, students may learn to depend on librarians. This is progress of a kind but hardly the sort of independence that should be encouraged.

If students are to function independently in the library, they must be taught more than the use of specific tools. Because evidence suggests that BI works best when related to the research needs of specific courses ${ }^{18}$ and students are more likely to retain information when they are actively involved in using it, instruction should not become too theoretical. Of course, balancing the practical with the theoretical in any discipline is never easy. BI librarians must continue to familiarize themselves-as well as students and faculty-with learning theory for instruction and the work of the cognitive theorists. ${ }^{19}$ This may help them to achieve the best combination of the theoretical and the pragmatic. $^{20}$

There is now greater emphasis in the BI literature on teaching students a conceptual framework, encouraging them to examine evidence rather than answer questions. ${ }^{21}$ Frick suggests that the way in which students obtain material for research may be more important than the material itself..$^{22}$ If we agree, instructors should work at presenting more than just specific titles and a bibliography in an attempt to teach what Frick calls "(1) discrimination or judgment and (2) an understanding of bibliographic structure. ${ }^{\prime 23}$ Frick offers four levels of bibliographic awareness: (1) specific titles useful for certain tasks, (2) types of sources, (3) knowledge of disciplines and the need for the use of different sources, and (4) knowledge of the structure of the literature. ${ }^{24}$ Teaching students how to learn is crucial if $\mathrm{BI}$ is to be more than first aid for a specific assignment. Another basic task is to prepare students for literacy in information gathering and use.

Until recently, bibliographic instruction has lacked a conceptual foundation. As a result, many librarians have been inadequately prepared for BI work. Relatively few librarians have studied learning theory or what has been called "social epistemology,'" an interdisciplinary study which supplies the scholarly underpinning for BI and focuses on how knowledge is generated, communicated, organized, and presented. Raymond G. McInnis' New Perspectives for Reference Service in Academic Libraries provides the best articulation of this "epistemological approach." He states that students should: 
... be informed, first, of the underlying processes and practices of inquiry characteristic of particular disciplines; second, of the patterns of the published research literature emanating from these activities; and third, that developing and refining research skills require thoughtful attention and deliberate practice. Three related premises are that there is a tacit logic of research strategy; that this logic can be raised to the level of awareness; and that research strategy itself can be refined by its intelligent and purposeful application. In short, it is desirable that students gain the craft skills of the instructorresearcher. ${ }^{25}$

Considerable effort must be expended to begin a BI program. Once the groundwork is established, the next step is to educate the faculty by demonstrating "the relationship of libraries, library use, and library instruction to these new ideas about educational methods. ${ }^{26}$ Convinced faculty can and often do persuade other faculty. If faculty lack an understanding about the need to develop a progression from elementary to advanced research techniques, then librarians must work to reorient them. Several writers have pointed out that "the faculty has limited understanding of the intellectual processes involved in sophisticated library competence. ${ }^{127}$ While some faculty do little or no library research, others do a great deal. Often, however, this is accomplished within the somewhat narrow confines of topic, method, or subdiscipline. Even successful researchers may not consciously understand the process they use and so may not be effective in helping undergraduates begin their research. All librarians have dealt with faculty who are reluctant to ask for help. Some may even admit that they have "forgotten" how to use the library, but few find it easy to admit to the need for help.

One of the most successful attempts to deal with this situation is described by Anne Grodzins Lipow in "Teaching the Faculty to Use the Library: A Successful Program of In-Depth Seminars for University of California, Berkeley, Faculty.'"28 The seminars are well advertised and well attended. Faculty response has been positive. Her conclusion is that:

... the myth that faculty won't admit to their lack of library know-how is exploded. We now know that (1) many, if not most, faculty need an update course; (2) many faculty need guidance in elementary concepts and tools in addition to the more advanced ones; (3) if given the opportunity, faculty want to be educated about the library; (4) although it is true that most faculty may neither understand nor appreciate the crucial role of librarians in the informationretrieval process, faculty can be educated about this role, and no one but librarians can do that job. ${ }^{29}$

Thus, the responsibility rests with librarians to absorb these ideas and develop ways of presenting them to faculty and students. As Beaubien notes, "Only when BI librarians grasp the substantive intellectual basis for what they have themselves been doing all along at the reference desk will they be able to teach their students to extrapolate to ever higher levels of complexity. ${ }^{\prime \prime 30}$ While the success of BI is highly dependent on teaching faculty, success with the faculty still depends upon librarians.

\section{CONCLUSION}

It is useful to consider why administrative concerns have been the focus of so much attention in the BI literature even if they are not as critical as other concerns discussed here. One answer is that administrative problems are the most visible and the most formidable when a program is initially undertaken. An indication of the maturity of the field is that now other factors more critical to the success of developed programs can be addressed.

The Earlham model of integrated instruction is a well-established, mature program that has addressed the problems discussed here. But before using Earlham's approach as a solution, it is important to recognize the uniqueness of Earlham's situation.

One important factor in our favor, for example, is the educational climate which encourages, even demands, library use. The size of most classes is small, and the faculty, who are concerned more with good teaching than research and publication, have built a curriculum that includes a variety of seminars, tutorials and independent study programs. A second factor permitting the program's development is the unusual rapport between librarians and teaching faculty. Such cooperation is essential. . . . ${ }^{31}$ Earlham's program is unique, and one must 
know the institutional context in order to understand it and appreciate it: our program-as indeed is true of most educational programswas designed for and has been shaped by its context; it is not an exportable package. ${ }^{32}$

Elsewhere, Farber refers to Earlham as the ideal context for library instruction and describes that context as a prelude to discussing the BI program itself. . $^{33}$

There are significant environmental factors affecting the problems of integration at Earlham but very few librarians could claim these as characteristic of their own institutions. ${ }^{34}$ Nonetheless, even at Earlham librarians have referred to the persistence of such problems as "too much library instruction, ",35 "student motivation, ${ }^{\prime \prime 36}$ and the critical relationship between librarians and teaching faculty."

While it is certainly instructive to see how Earlham has resolved its problems, we must recognize Earlham's singular qualities as we seek out solutions that draw on the particular strengths and unique qualities of our own institutions.

Whatever the institutional environment, BI instructors must be flexible and creative by introducing new research strategies and techniques into changing curricula and tailoring them to meet student needs. Two additional guidelines can be offered:

1. Establish collegial relationships with the teaching faculty beyond the classroom/BI interaction. If the goals are to reach other classes and other faculty, to make more creative use of BI, and to develop more intensive skills in students, then we must have the trust of the faculty and a shared belief that what we have to offer is important and valuable. Development of trust and the sharing of values are not simply the result of classroom lectures or presentations to faculty meetings on BI. Participation on campus-wide committees, informal interaction, attendance at departmental seminars and presenta- tions, cooperative development of the library collection, and many other activities unique to each individual campus all contribute to establishing the kind of relationships with faculty that are necessary for successful, integrated BI.

2. Maintain an awareness that the opinions and comments of students about BI presentations are valuable and should be heeded. There is a temptation to regard student complaints about BI as unsolvable or simply invalid and therefore to disregard them. Teaching faculty struggle constantly with the problem of how much weight to give student evaluations. This is no less difficult in BI. Yet regardless of the accuracy of a student complaint, it should be addressed by the librarian. The worst approach is to assume that the librarian knows best and to continue as before. While complaints may not impress the librarian, they can influence the faculty who may tire of defending the inclusion of $\mathrm{BI}$ in the classroom and discontinue their involvement.

This paper has explored the critical role of teaching faculty in integrated instruction and the issues of consistency and transference. A careful reading, however, will show that these two themes are related. Consistency and transference are two particularly important outcomes of the relationship between librarians and faculty. They deserve special, separate attention.

Our intention has not been to criticize the relationship between teaching faculty and librarians. Like most partnerships there are problems that must be worked out. The better each partner understands the other and the important role each plays in the achievement of mutually shared goals, the healthier the relationship will be and the more likely it is that the partnership will be a long and successful one.

\section{REFERENCES}

1. See Hannelore B. Rader, "Bibliographic Instruction: Is It a Discipline?" Reference Services Review 10:75-76 (Winter 1982).

2. Anne K. Beaubien, Sharon A. Hogan, and Mary W. George, Learning the Library (New York: Bowker, 1982), p.5. 
3. F. L. Hopkins, "Century of Bibliographic Instruction: The Historical Claim to Professional and Academic Legitimacy," College and Research Libraries 43:192-198 (May 1982).

4. Beaubien, Learning the Library, p.46-49.

5. Anne F. Roberts, Library Instruction for Librarians (Littleton, Colo.: Libraries Unlimited, 1982), p.62.

6. Ibid., p.63.

7. Beverly Renford and Linnea Hendrickson, Bibliographic Instruction: A Handbook (New York: NealSchuman, 1980), p.74.

8. Sharon J. Rogers, "Class-Related Bibliographic Instruction: A Philosophical Defense," in Proceedings from the Southeastern Conference on Approaches to Bibliographic Instruction (Charleston, S.C.: College of Charleston Library Associates, 1980), p.25.

9. Renford, Bibliographic Instruction, p.76.

10. Ibid.

11. Beaubien, Learning the Library, p.159.

12. Ibid.

13. Raymond G. McInnis, New Perspectives for Reference Service In Academic Libraries (Westport, Conn.: Greenwood, 1978), p.3.

14. Ibid., p.xx.

15. James R. Kennedy, "Integrated Library Instruction," Library Journal 95:1452 (Apr. 15, 1970).

16. Ibid., p. 1451.

17. David Carlson, "Library Instruction Program: Clifford Memorial Library, University of Evansville, Indiana"' (Arlington, Va.: ERIC Document Reproduction Service, ED 225 594, 1983).

18. Jacquelyn M. Morris, "A Philosophical Defense of a Credit Course," In Proceedings from the Southeastern Conference on Approaches to Bibliographic Instruction (Charleston, S.C.: College of Charleston Library Associates, 1980), p.25.

19. See, for example, Robert M. Gagné, The Conditions of Learning, 3d ed. (New York: Holt, 1977); Jerome S. Bruner, J. J. Goodnow, and G. A. Austin, A Study of Thinking. (Huntington, N.Y.: Robert E. Krieger, 1977).

20. Two examples of BI applications are Constance R. Miller, "Scientific Literature as Hierarchy: Library Instruction and Robert M. Gagné," College and Research Libraries 43:385-90 (Sept. 1982); Pamela Kobelski and Mary Reichel, "Conceptual Frameworks for Bibliographic Instruction," Journal of Academic Librarianship 7:73-77 (May 1981).

21. Topsy N. Smalley, "Bibliographic Instruction in Academic Libraries: Questioning Some Assumptions," Journal of Academic Librarianship 3:283 (Nov. 1977). See also Jon Lindgren, "The Idea of Evidence in Bibliographic Inquiry," in Theories of Bibliographic Education; Designs for Teaching, ed. by Cerise Oberman and Katina Strauch (New York: Bowker, 1982), p.27-46.

22. Elizabeth Frick, "Teaching Information Structure: Turning Dependent Researchers into SelfTeachers," in Theories of Bibliographic Education: Designs for Teaching, ed. by Cerise Oberman and Katina Strauch (New York: Bowker, 1982), p.205.

23. Ibid., p.197.

24. Ibid., p.198.

25. McInnis, New Perspectives, p.xx.

26. Thomas G. Kirk, "Problems in Library Instruction in Four-Year Colleges," in Educating the Library User, ed. by John Lubans, Jr. (New York: Bowker, 1974), p.88.

27. Patricia Knapp. The Library, the Undergraduate and the Teaching Faculty (San Diego: University Library, University of California, 1970), p.6.

28. Anne Grodzins Lipow, "Teaching the Faculty to Use the Library: A Successful Program of InDepth Seminars for University of California, Berkeley, Faculty," in New Horizons for Academic Libraries, Proceedings of First National ACRL Conference (Boston, 1978), ed. by Robert Stueart and Richard Johnson (New York: K. G. Saur, 1979), p.262-67.

29. Ibid., p.267.

30. Beaubien, Learning the Library, p.4.

31. Kennedy, "Integrated Library Instruction," p.1452.

32. Evan I. Farber, "Library Instruction Throughout the Curriculum: Earlham College Program," in Educating the Library User, ed. by John Lubans, Jr. (New York: Bowker, 1974), p.145.

33. Ibid., p.145-48.

34. Ibid., p. 148.

35. Kennedy, "Integrated Library Instruction," p.1452.

36. Ibid.

37. Farber, "Library Instruction," p.147. 


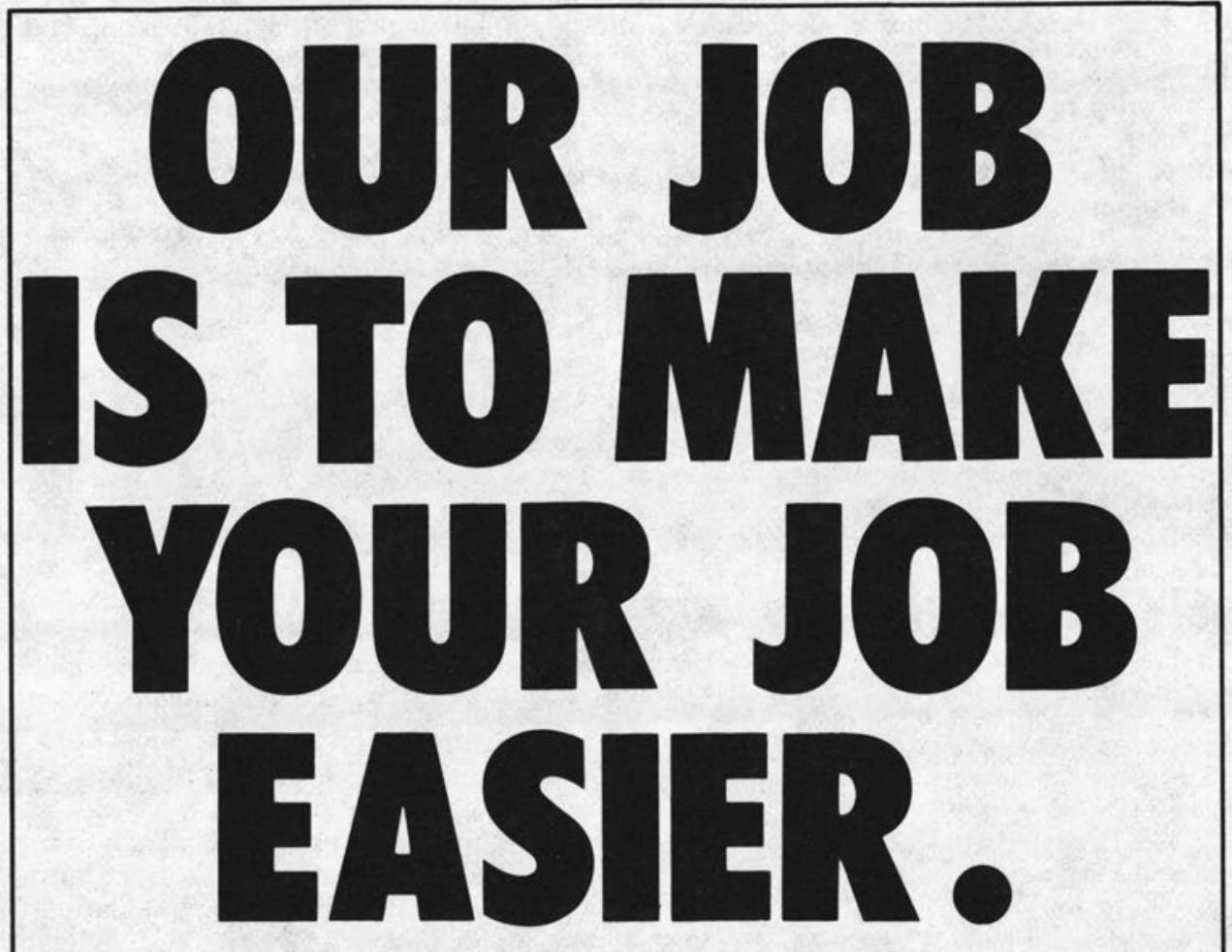

All EBSCO systems are designed with one major goal in mind: to simplify your serials transactions. No matter how big your library is, how small, or how specialized, we can provide the professional services you expect.

\section{CONTACT EBSCO-LET'S TALK SERVICE.}

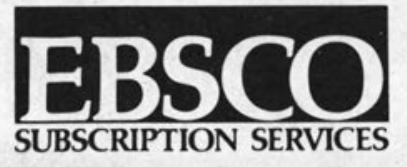

P.O. Box 1943, Birmingham, AL 35201, (205) 991-6600 